\title{
Scope of surgery for intracranial aneurysm in the elderly: a preliminary report
}

\author{
R P SENGUPTA, L P LASSMAN, J HANKINSON
}

British Medical fournal, 1978, 2, 246-247

\section{Summary and conclusions}

Thirty-two elderly patients were reviewed six months to six years after intracranial surgery for subarachnoid haemorrhage. Out of 24 patients whose surgical outcome had been satisfactory, one had died from an unrelated illness and the remainder were well and leading normal lives. Eight patients had a poor outcome, which in some cases was due to factors other than age. In only three could a poor outcome be attributed to early surgery and advanced age.

The results confirm that in at least three-quarters of patients aged 60-65 the risk of further haemorrhage can be removed by surgery without causing a major neurological deficit.

\section{Introduction}

Despite the catastrophic effects of subarachnoid haemorrhage from a ruptured intracranial aneurysm, ${ }^{1}$ intracranial surgery is often confined to young age groups. But as a result of recent advances these aneurysms can now be obliterated safely from the cerebral circulation and further bleeding prevented in elderly patients. We have reviewed patients aged 60 and over who had undergone operation at this centre for ruptured intracranial aneurysms and decided to report our findings after Martindale and Garfield ${ }^{3}$ expressed doubt about the value of investigation and treatment in the elderly.

\section{Patients and methods}

During the past six and a half years 32 patients aged over 60 with ruptured intracranial aneurysms have been treated surgically. They constituted most of the patients in this age group who were referred to the centre with subarachnoid haemorrhage and found to have intracranial aneurysms by angiography. Data on the few who did not corne to surgery because of their rapidly deteriorating condition from cerebral infarction or because they refused surgery will be analysed separately. Otherwise there was no selection on the basis of age, associated hypertension or other chronic illness, or the size, location, or multiplicity of intracranial aneurysms. Two patients in this age group with intracranial aneurysms presenting as space-occupying lesions were also successfully treated surgically but are not included here.

Table I gives the age distribution of the 32 patients. Twenty-three were women, which suggests a greater incidence of intracranial aneurysms in elderly women than men. Associated chronic illness was found in eight patients-hypertension in five, chronic respiratory disease in two, and chronic pericarditis in one.

Clinical condition on admission and at operation was assessed according to Botterell's classification. ${ }^{4}$ On admission there were 11 patients in grade I, 12 in grade II, 2 in grade III, 6 in grade IV, and

\footnotetext{
Regional Neurological Centre, Newcastle General Hospital, Newcastle upon Tyne NE4 6BE

R P SENGUPTA, MSC, FRCs, consultant neurosurgeon

L P LASSMAN, FRCS, consultant neurosurgeon

J HANKINSON, FRCS, professor of neurosurgery
}

1 in grade $\mathrm{V}$. At operation, however, the numbers in these grades were $11,16,4,0$, and 1 respectively. The patient in grade $\mathrm{V}$ on admission improved to grade III at operation. The patient in grade $V$ at operation (evacuation of a large haematoma) was admitted in grade IV but deteriorated from a second haemorrhage after initial improvement.

Thirty-six aneurysms were discovered by angiography. Vertebral angiography was carried out only when bilateral carotid angiography failed to disclose the source of haemorrhage. There were 14 anterior communicating aneurysms, 12 posterior communicating, four middle cerebral, three carotid bifurcation, and two carotid-ophthalmic; only one was in the posterior circulation-namely, at the junction of the basilar and superior cerebellar arteries.

Interestingly, all the middle cerebral aneurysms were found incidentally, and none was considered to be responsible for the haemorrhage. This noticeable lack of middle cerebral aneurysms causing subarachnoid haemorrhage in the elderly confirms that these aneurysms rarely cause recurrent haemorrhage in later years if the patient has survived haemorrhage in the middle years. ${ }^{5}$

All aneurysms were treated by intracranial surgery except in two patients with carotid-ophthalmic aneurysms. In both cases part of the neck appeared to be extradural and they were treated by common carotid ligation. In one 64-year-old patient an incidental middle cerebral aneurysm was obliterated at a second operation three months after obliteration of the offending anterior communicating aneurysm. In a second patient another incidental middle cerebral aneurysm was clipped simultaneously with the offending ipsilateral posterior communicating aneurysm. Two other incidental middle cerebral aneurysms were left untreated. Controlled hypotension was used in varying degrees during the operation and the aneurysm occluded with a spring-loaded clip by a uniform technique. The occluded aneurysm was then invested with muslin.

After surgery angiography was repeated to check the completeness of the aneurysmal obliteration. The neck was obliterated with a clip in 31 aneurysms in 29 cases. In one the aneurysm was wrapped, as application of a clip at operation proved difficult.

\section{Results}

Table I gives the outcome of surgery in the 32 patients. Good outcome denotes the ability to resume previous employment, which in these elderly patients was mostly housework; "fair" means the ability to look after oneself; and "poor" indicates total disablement.

TABLE I-Age distribution of patients and outcome of surgery

\begin{tabular}{c|c|c|c|c|c|c|c|c|c|c}
\hline \multirow{2}{*}{ Outcome } & & & & \multicolumn{2}{|c|}{ Age (years) } & Total \\
\hline $\begin{array}{c}\text { Good } \\
\text { Fair }\end{array}$ & 7 & 61 & 62 & 63 & 64 & 65 & 69 & 70 & 71 & \\
$\begin{array}{c}\text { Poor } \\
\text { Dead }\end{array}$ & & 1 & 2 & 2 & 7 & 1 & & & 1 & 21 \\
\hline Total & 7 & 1 & 1 & & & & 1 & 1 & & 3 \\
3 & 5 & 3 & 7 & 2 & 1 & 3 & 1 & 32 \\
\hline
\end{tabular}

Between the ages of 60 and 65 there was no influence of age on outcome. Of five patients aged 69-71, four had a poor or fatal outcome, but in some of these other factors were contributory.

Table II summarises the factors causing complications in the eight patients with a poor outcome. In cases 4 and 32 the poor outcome was due to avoidable technical failure. Poor results in cases 1 and 22 could be expected from the radiological evidence of congenital anomalies in the circle of Willis. ${ }^{6}$ Apart from the patient in grade $\mathrm{V}$ (case 27) the remaining patients (cases 11, 14, and 16) had poor results owing to either early surgery or advanced age. Twenty-four patients $(75 \%)$ had a satisfactory outcome. 
TABLE II-Factors causing complications in eight patients with poor or fatal outcome

\begin{tabular}{|c|c|c|c|c|c|}
\hline $\begin{array}{l}\text { Case } \\
\text { No }\end{array}$ & $\underset{\text { (years) }}{\text { Age }}$ & $\mid \begin{array}{c}\text { Grade at } \\
\text { operation }\end{array}$ & $\begin{array}{c}\text { Interval } \\
\text { (days) }\end{array}$ & $\underset{\text { treated }}{\text { Aneurysm }}$ & $\begin{array}{l}\text { Specific factors } \\
\text { causing complication }\end{array}$ \\
\hline 1 & 62 & II & 20 & $\begin{array}{l}\text { Posterior } \\
\text { communicating }\end{array}$ & $\begin{array}{l}\text { Occlusion of fetal posterior } \\
\text { cerebral artery with } \\
\text { aneurysm causing } \\
\text { hemiplegia. Chronic } \\
\text { emphysema }\end{array}$ \\
\hline 4 & 70 & III & 12 & $\begin{array}{l}\text { Posterior } \\
\quad \text { communicating }\end{array}$ & $\begin{array}{l}\text { Giant aneurysm when } \\
\text { clipped caused severe } \\
\text { kinking of internal } \\
\text { carotid artery resulting } \\
\text { in hemiplegia }\end{array}$ \\
\hline 11 & 61 & II & 6 & $\begin{array}{l}\text { Posterior } \\
\text { communicating; } \\
\text { middle cerebral }\end{array}$ & $\begin{array}{l}\text { Oedematous brain at } \\
\text { operation. Postoperative } \\
\text { cerebral infarction }\end{array}$ \\
\hline 14 & 62 & III & 11 & $\begin{array}{l}\text { Anterior } \\
\text { communicating }\end{array}$ & $\begin{array}{l}\text { Postoperative vasospasm } \\
\text { two days later causing } \\
\text { cerebral infarction }\end{array}$ \\
\hline 16 & 70 & II & 25 & $\begin{array}{l}\text { Internal carotid } \\
\text { bifurcation }\end{array}$ & $\begin{array}{l}\text { Haemorriagic problem at } \\
\text { operation from small } \\
\text { vessels of brain. Known } \\
\text { hypertensive }\end{array}$ \\
\hline 22 & 69 & II & 10 & $\begin{array}{l}\text { Anterior } \\
\text { communicating }\end{array}$ & $\begin{array}{l}\text { Congenital fusion of both } \\
\text { anterior carotid arteries. } \\
\text { Postoperative vasospasm } \\
\text { Causing hemiplegia }\end{array}$ \\
\hline 27 & 70 & V & 2 & Posterior & Cerebral infarction \\
\hline 32 & 65 & I & 10 & $\begin{array}{l}\text { Communicating } \\
\text { Posterior } \\
\text { communicating }\end{array}$ & $\begin{array}{l}\text { Giant aneurysm. Clip } \\
\text { slipped two hours later } \\
\text { causing fatal } \\
\text { haemorrhage }\end{array}$ \\
\hline
\end{tabular}

Follow-up-All surviving patients were traced, the follow-up periods ranging from six months to six years. Of the three patients who survived in poor condition, two died in another hospital and the other was in an institution. Of the 24 patients with a satisfactory surgical outcome, one died from an unrelated illness after resuming his office work. The remainder were well and leading a normal life. Interestingly the three patients who were classed as "fair" on discharge had greatly improved and could be classed as "good"

\section{Discussion}

The natural history of subarachnoid haemorrhage is bleak, ? and a ruptured intracranial aneurysm remains a threat for the rest of life. It was hoped that the introduction of antifibrinolytic drugs would solve the problem of recurrent haemorrhage from intracranial aneurysms, ${ }^{8}$ and we showed ${ }^{9}$ that these drugs are highly effective in preventing recurrent haemorrhage before intracranial surgery is undertaken. Other studies, ${ }^{10} 11$ however, proved that antifibrinolytic drugs do not guarantee protection against future haemorrhage.

We do not share the enthusiasm ${ }^{12}$ for non-surgical management of ruptured intracranial aneurysms with prolonged antifibrinolysis because of our experiences with this treatment in a large series of patients. Moreover, a $24^{\circ}$, incidence of recurrent haemorrhage with increasing morbidity after antifibrinolytic treatment cannot be regarded as very effective. Surgically obliterating the aneurysm from the circulation is the only protection against catastrophe. Since the mortality and morbidity from subarachnoid haemorrhage are greater in the elderly ${ }^{2}$ the need for surgery must be balanced against its risk in those of advanced years. The surgical outcome in this series confirms that at least three-quarters of patients in the 60-65-year age group can be made safe from future haemorrhage without inflicting major neurological deficit. Unplanned surgery for ruptured intracranial aneurysm does not improve the chances of useful survival in any age group; its results are likely to be worse in the elderly with poor cardiorespiratory states. Nevertheless, the chronological age of the patient does not always correlate with physiological age. Thus a patient in his 50 s may have a physiological age of 70 and vice versa. Elderly patients need not therefore be excluded from the benefits of surgery just because of their chronological age.

On the basis of clinical economics, Martindale and Garfield ${ }^{3}$ preferred to undertake neurosurgery in patients with cerebral tumour and spinal cord compression rather than in elderly patients with subarachnoid haemorrhage. Although many cerebral tumours and cord compressive lesions in the elderly are malignant, often with a poor surgical outcome, these patients should be admitted to a neurosurgical ward, but not necessarily at the expense of patients with a benign condition. If elderly patients can be treated actively for conditions such as fracture of the neck of the femur, intestinal obstruction, and dissecting aortic aneurysm there is no reason why they should not be considered for treatment of a ruptured intracranial aneurysm, provided the surgeon believes that the result will be superior to the natural course of the disease.

\section{References}

1 Walton, J N, Subarachnoid Haemorrhage. Edinburgh and London, Livingstone, 1956.

${ }^{2}$ Keller, A Z, American fournal of Epidemiology, 1970, 91, 139.

${ }^{3}$ Martindale, B V, and Garfield, J, British Medical fournal, 1978, 1, 465.

${ }^{4}$ Botterell, G, et al, fournal of Neurosurgery, 1956, 13, 1.

5 Sengupta, R P, "Anterior Communicating Aneurysms and their Management by Direct Surgery," thesis, University of Newcastle, 1977.

${ }^{6}$ Sengupta, R P, Neurochirurgia, 1975, 18, 33.

${ }^{7}$ Drake, C G, Proceedings of the Royal Society of Medicine, 1971, 64, 477.

${ }^{8}$ Plum, P F, cited by C H Millikan, Stroke, 1974, 5, 429.

${ }^{9}$ Sengupta, R P, So, S C, and Villarejo-Ortega, F J, fournal of Neurosurgery, 1976, 44, 479.

${ }^{10}$ Post, K D, et al, fournal of Neurosurgery, 1977, 46, 290.

11 Fodstad, H, personal communication, 1977.

${ }^{12}$ Maurice-Williams, R S, British Medical fournal, 1978, 1, 945.

(Accepted 15 May 1978)
ONE HUNDRED YEARS AGO Professor Hoffmann has published an essay containing the results of his researches on the immediate cause of death by hanging, of which the fournal de Médecine gives a short abstract. In hanging, the noose does not press directly on the larynx and the trachea, but almost always slips between the larynx and the chin. In these cases, the basis of the tongue is pushed upwards and pressed against the posterior wall of the pharynx, completely closing it. The truth of this assertion can easily be proved by making sections of frozen bodies of persons that have been hung. The most important agent, however, in this kind of death, is the compression of the larger vessels and the cervical portion of the vagus nerve; the upper portion of the carotid being pressed against the transverse processes of the cervical vertebrae before it branches off into the external and internal carotids, and the inner coat of the vessel being ruptured. The jugular veins are compressed at the same time; and the brain can neither receive any more blood nor allow that which it contains already to flow away; its irritability is, therefore, extinct. The very important part which both the vagus and the vessels take in causing death by hanging is clearly shown through the following observations. 1. Loss of consciousness following immediately the compression caused by the rope at the moment when the noose is drawn tight by the weight of the body. The truth of this assertion is proved by the fact that no person who commits suicide by hanging ever attempts to rid himself of the rope which throttles him, although he might do so easily by standing upright, as the body is not always suspended above the surface of the ground. 2 . The rapidity with which death ensues and the beating of the heart stops. The few straggling respirations which generally occur in asphyxia shortly before death have not been observed in persons who have been hung. It is also well known how difficult it is to restore such patients to life. It is clearly seen from the above mentioned facts, that death occasioned by hanging cannot be explained simply by obstruction of the respiratory tracts, but that, on the contrary, the compression of the nerves and vessels of the neck is the principal agent. All these facts, however, not only apply to hanging, but to all methods of strangulation. It has also been proved that it is possible to commit suicide by pressing with both hands on the sides of the neck for a sufficiently long time, and it is well known that in this way the pulsations of the heart have been stopped and consciousness lost. (British Medical fournal, 1878.) 